\title{
A thrombocyte consumption test for the demonstration of autoantibody-like serum factors
}

\author{
GY. DÓBIÁS ${ }^{1}$ \\ From the Municipal Hospital, Budapest
}

SYNOPSIS The capacity of blood platelets to attach themselves aspecifically to antigen-antibody complexes in the presence of complement can be utilized for the demonstration of antibodies formed against homologous tissues.

A mixture of the serum-, antigen-complement, and of human thrombocytes is incubated, and the number of thrombocytes in the supernatant is ascertained and referred to a standard. Measurements less than $85 \%$ of the standard are regarded as positive.

Sera collected from patients with 'protracted' acute or chronic hepatitis and cirrhosis were found to be positive with the new method in $68.0 \%$ of the cases; the corresponding figures were $26.3 \%$ for 'non-protracted' acute hepatitis and $18.1 \%$ for diseases of the bile duct. No positive reaction occurred in other internal diseases studied or in healthy persons, but $40 \%$ of subjects with diverse infections gave positive results possibly because of autoantibody formation against tissues damaged by the infections. Comparative examinations suggest that the thrombocyte consumption test is more specific than the antihuman globulin consumption method.

In the presence of all components of complement (Siqueira and Nelson, 1961) blood platelets are aspecifically attached to the complex formed by corpuscular (Lamanna, 1957; Nelson and Nelson, 1959) and soluble antigens (Miescher and Cooper, 1960; Osler, Hawrisiak, Ovary, Siqueira, and Bier, 1957; Siqueira and Nelson, 1961) with their antibodies. This might explain why in states of allergy (Stavitsky, Stavitsky, and Ecker, 1949; Rocha e Silva, 1950; Storck, 1951; Storck, Hoigné, and Koller, 1951; Nilzén, 1953; Rice, 1955; Storck, and Hoigné, 1956; Korossy and Gózony, 1959; Bier and Siqueira, 1959) the thrombocyte count diminishes significantly after the administration of homologous antigen. Although it is only in recent years that investigators have gained some insight into these processes, Rieckenberg employed thrombocytes as a specific indicator system for the examination of Leptospira and Trypanosoma antibodies as far back as the year 1917. Hoigné and Storck elaborated in 1953 a thrombocyte-agglutination procedure for the diagnosis of drug sensitivity.

The present investigations were instituted to decide

${ }^{1}$ Present address: Postgraduate Medical School, Budapest, XIII Szabolcs-utca 33, Hungary.

Received for publication 17 September 1962 if the decrease in the thrombocyte count after antigen-antibody reactions could be used to detect autoantibodies against homologous tissues and organs. The sera of patients suffering from various hepatic disorders were tested, and homogenized human liver was employed as antigen. We compared the results of examinations with the antihuman globulin consumption test carried out simultaneously.

\section{MATERIALS AND METHODS}

ANTIGEN The livers of young persons who had died accidentally were washed a few hours after death with 20 1. of ice-cold physiological saline through a cannula inserted into the portal vein, and then homogenized in a Waring blender. The liver brei was washed with ice-cold physiological saline until the last washing fluid gave a negative reaction for protein with a $20 \%$ solution of sulphosalicylic acid. The washed liver suspension was then distributed in $1 \mathrm{ml}$. ampoules and stored at $-20^{\circ} \mathrm{C}$. The content of each ampoule was suspended in $24 \mathrm{ml}$. of sterile veronal buffer ${ }^{2}$ at $p \mathrm{H} 6.0-6.2$ before use. The antigen suspension contained 5 to $10 \mathrm{mg} . / \mathrm{ml}$. of dry matter.

'Sodium chloride, 8.38 g., 5, 5-diethyl barbituric acid, $0.46 \mathrm{~g}$., sodium 5.5-diethyl barbital 0.30 g., sodium bicarbonate 0.25 g., magnesium sulphate, $0.012 \mathrm{~g}$., and water to $200 \mathrm{ml}$. 
CLINICAL MATERIAL The patients were grouped clinically as follows: 44 cases of acute infective hepatitis, chronic hepatitis, or cirrhosis; 11 of cholecystitis; 15 of other internal diseases, comprising hyperthyroidism, generalized arteriosclerosis, heart injuries, hypertension; 15 of various infectious diseases comprising pneumococcal pneumonia, acute pharingitis, influenza, acute tonsillitis, Bact. coli sepsis, and infectious mononucleosis. Fourteen healthy individuals were included in the trial. Blood was taken from the patients two to five times at weekly intervals; the 14 healthy individuals had only one bleeding. Two hundred and fifty samples were thus collected. The sera of patients were preserved sterile at $-20^{\circ} \mathrm{C}$. without the addition of any preservative.

STANDARD SERA Sera from five healthy persons were used as standards. The arithmetical mean of the thrombocyte count of these sera was used as the reference serum for values obtained from the test sera. It is advisable to retain large amounts of standard sera for continual reference throughout the tests.

THROMBOCYTE SUSPENSION Human blood platelets were used. Blood, drawn separately for each test from the cubital vein of healthy donors, was collected in a paraffin- or silicone-coated graduated centrifuge tube containing enough $3.8 \%$ sodium citrate to form a 1:5 mixture with the added blood. After centrifuging this mixture for eight minutes at 500 r.p.m., the thrombocyte count in the supernatant fluid was determined. A suspension containing 200,000 to 240,000 thrombocytes/c.mm. was used; if the value turned out to be higher, centrifugation was continued until the desired density was reached when the plasma was transferred to a paraffin-coated test tube, gently stirred, and used without delay. All superfluous mechanical operations which might damage the platelets, e.g., pouring or shaking, must be avoided. The whole procedure should be quick: no more than half an hour must elapse between the withdrawal of blood from the donor and its application.

REACTION Carefully cleaned test tubes $(70 \times 8 \mathrm{~mm}$.), pretreated with sulphuric acid, were employed for the test. The ingredients were pipetted from accurately calibrated pipettes in the following order: $0.5 \mathrm{ml}$. of the serum to be tested (or $0.5 \mathrm{ml}$. of the standard sera), $0.1 \mathrm{ml}$. of the thrombocyte suspension (in the plasma containing fresh

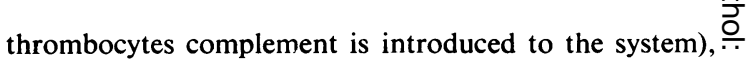
and $0.4 \mathrm{ml}$. of antigen suspension. The test tubes were gently shaken and placed in a $37^{\circ} \mathrm{C}$. water bath for $\stackrel{\mathcal{O}}{+}$ 30 minutes. Shaking was repeated at 15 minutes. After incubation, the tubes were left at room temperature for $\overline{\bar{O}}$ 10 minutes, and then the number of thrombocytes per $\frac{\bar{\omega}}{\partial}$ $0.01 / \mathrm{c} . \mathrm{mm}$. of the supernatant was determined. As the $\mathbb{\mathbb { D }}$ process is based on the linking of part of the thrombocytes added to the system, the method has been called the thrombocyte consumption test.

Not more than 20 sera were tested together so that the whole procedure could be finished within two $\vec{\omega}$ hours from pipetting the ingredients.

THROMBOCYTE COUNT The chamber method of Hegedüs $\vec{\sigma}$ (Bálint and Hegedüs, 1959) was employed. A few drops ir of the supernatant were aspirated from the test tubes by paraffin-coated Pasteur pipettes and filled both fields of the $\overrightarrow{ }$

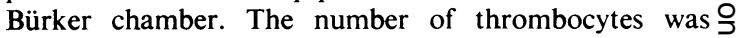
determined in five rectangles per field, and the results $\rightarrow$ added. The total represented the thrombocyte count per $\mathcal{P}$ $0.01 / \mathrm{c} . \mathrm{mm}$. of the supernatant. (Where the distribution of thrombocytes is uneven, 10 rectangles per field are $\frac{\mathbb{D}}{3}$ counted, and the result divided by 2.) The margin of error is negligible: if the tests are performed with precision, the extreme values of the standard sera will remain within the $\vec{\oplus}$ limits of $x+5 \frac{x}{100}$ where $x=$ the arithmetical mean of the number of thrombocytes in the standard sera.

ANTIHUMAN GLOBULIN CONSUMPTION TEST The consump-Ō tion test was performed according to Steffen's original description (Steffen, 1954; 1955; Steffen and Schindler, ® 1955) with the antigen referred to above. The reaction was $\overrightarrow{\vec{B}}$ considered positive provided that the Coombs serum showed a twofold or even bigger decrease in titre.

\section{RESULTS}

The number of thrombocytes in the test sera, expressed as the percentage of the arithmetical mean of the thrombocyte values in the standards, is shown ino Table I. In about a third of the test sera the number of thrombocytes was between 80 and $90 \%$ of the을 standard; in the remainder the results were below $80 \mathrm{D}$ and above $90 \%$ in descending sequence. The results

TABLE I

DECREASE IN THROMBOCYTE COUNT ACCORDING TO DISEASE

\begin{tabular}{|c|c|c|c|c|c|c|}
\hline \multirow[t]{2}{*}{ Diagnosis } & \multirow{2}{*}{$\begin{array}{l}\text { Number of } \\
\text { Serum } \\
\text { Samples }\end{array}$} & \multicolumn{5}{|c|}{$\begin{array}{l}\text { Percentage of Arithmetical Mean of Thrombocyte Count in } \\
\text { Standard Sera (arithmetic mean of standards }=: 100 \% \text { ) }\end{array}$} \\
\hline & & $<70 \%$ & $70-79 \%$ & $80-89 \%$ & $90-99 \%$ & $\geq 100 \%$ \\
\hline 'Protracted' acute hepatitis', chronic hepatitis, cirrhosis & 113 & 8 & 27 & 44 & 18 & 16 \\
\hline 'Non-protracted' acute hepatit is ${ }^{2}$ & 59 & 2 & 6 & 17 & 15 & 19 \\
\hline Cholecystitis, obstructive jaundice & 26 & 0 & 0 & 6 & 12 & 8 \\
\hline Healthy persons & 14 & 0 & 0 & 0 & 7 & 7 \\
\hline
\end{tabular}

'Time in hospital more than 6 weeks; average, 57 days ' $T$ ime in hospital less than 6 weeks; average, 26 days 
TABLE II

RESULTS OF ANTIHUMAN GLOBULIN AND THROMBOCYTE CONSUMPTION TESTS IN THE EXAMINED PATIENTS

\begin{tabular}{|c|c|c|c|c|c|}
\hline \multirow[t]{2}{*}{ Diagnosis } & \multirow[t]{2}{*}{$\begin{array}{l}\text { No. of } \\
\text { Patients }\end{array}$} & \multicolumn{2}{|c|}{$\begin{array}{l}\text { Thrombocyte Consumption } \\
\text { Test }\end{array}$} & \multicolumn{2}{|c|}{$\begin{array}{l}\text { Antihuman Globulin Con- } \\
\text { sumption Test }\end{array}$} \\
\hline & & Positive & Negative & Positive & Negative \\
\hline $\begin{array}{l}\text { 'Protracted' acute hepatitis, chronic hepatitis, cirrhosis } \\
\text { 'Non-protracted' acute hepatitis } \\
\text { Cholecystitis, obstructive jaundice } \\
\text { Various infections } \\
\text { Other internal diseases } \\
\text { Healthy persons }\end{array}$ & $\begin{array}{l}25^{1} \\
19 \\
11 \\
15 \\
15 \\
14\end{array}$ & $\begin{array}{l}17(68.0 \%) \\
4(26 \cdot 3 \%) \\
2(18 \cdot 1 \%) \\
6(40.0 \%)^{2} \\
0(0.0 \%) \\
0(0.0 \%)\end{array}$ & $\begin{array}{c}8(32.0 \%) \\
15(73.7 \%) \\
9(81.9 \%) \\
9(60.0 \%) \\
15(100.0 \%) \\
14(100.0 \%)\end{array}$ & $\begin{array}{r}19(76.0 \%) \\
9(47.5 \%) \\
3(27.2 \%) \\
9(60.0 \%) \\
3(20.0 \%) \\
2(14.2 \%)\end{array}$ & $\begin{array}{r}6(24.0 \%) \\
10(52.5 \%) \\
8(72.8 \%) \\
6(40.0 \%) \\
12(80.0 \%) \\
12(85.8 \%)\end{array}$ \\
\hline
\end{tabular}

'Protracted' acute hepatitis 18 , chronic hepatitis 4 , cirrhosis 3

${ }^{2}$ The six positive cases of diverse infections comprised pneumococcal pneumonia 2 , infectious mononucleosi 1 , influenza 2 , Bact. coli sepsis 1.

TABLE III

EFFECT OF CORTICOSTEROID TREATMENT ON THROMBOCYTE CONSUMPTION TEST IN 17 POSITIVE PATIENTS IN THE FIRST GROUP OF TABLE II

\begin{tabular}{|c|c|c|c|c|}
\hline & \multicolumn{2}{|c|}{ Thrombocyte Consumption Test } & \multicolumn{2}{|c|}{ Antihuman Globulin Test } \\
\hline & Positive & Negative & Positive & Negative \\
\hline $\begin{array}{l}\text { During steroid treatment } \\
\text { Before and after steroid treatment }\end{array}$ & $\begin{array}{r}7(36.8 \%) \\
26(63.4 \%)\end{array}$ & $\begin{array}{l}12(63 \cdot 2 \%) \\
15(36.6 \%)\end{array}$ & $\begin{array}{r}7(35 \cdot 0 \%) \\
30(73 \cdot 1 \%)\end{array}$ & $\begin{array}{l}13(65.0 \%) \\
11(26.9 \%)\end{array}$ \\
\hline
\end{tabular}

are different if the test sera are divided into categories according to clinical diagnosis. Most of the sera obtained from patients suffering from protracted acute or chronic hepatitis and cirrhosis contained fewer thrombocytes than $90 \%$ of the standard, but this value was above $90 \%$ in most cases in the sera of other patients and in the healthy persons. Table I shows that there is a correlation between the clinical picture and the decrease in the thrombocyte count.

The boundary between positively and negatively reacting test sera was found to be at $85 \%$ of the standard, and at this level the best correlation with the clinical state as well as with the results of the antihuman globulin consumption test carried out at the same time (Table II) was found. Test sera with a thrombocyte count below this value will be termed 'positive' and those above it will be called 'negative'. 'Negative' only applies to those patients whose sera had never given a positive reaction. Seventeen patients of the first group in Table II were 'positive' so serum from these patients was collected on 60 occasions, and positive reactions in 33 and negative in 27 instances were obtained. The reaction turned most frequently negative when the patient had received corticosteroids (Table III), a finding in accordance with the results of Vorländer (1954), Rissel, Steffen, and Wewalka (1957), Osztovics, Marcsek, and Szász (1962). One or two days after starting administration of steroids the positive thrombocyte consumption test became negative, but a few days after ending the treatment it became positive again (Vorländer, 1954; Rissel et al., 1957).
The most pronounced reduction in the thrombocyte count, i.e., the most strongly positive case, was $48.2 \%$ of the standard. To study the reproducibility of the thrombocyte consumption test, 25 sera selected at random were analysed successively and the same results were obtained in $\mathbf{7 6 . 8 \%}$. Equivalent results seemed to be most frequent in sera which had been repeatedly frozen and thawed.

In some instances, thrombocytes showed fragmentation after the reaction. Since thrombocytes

\section{TABLE IV}

COMPARATIVE TESTS WITH LIVER AND HEART ANTIGEN

\begin{tabular}{llcc}
$\begin{array}{l}\text { Serial } \\
\text { No. of } \\
\text { Cases }\end{array}$ & Diagnosis & Antigen & \\
\cline { 3 - 4 } & & Liver & Heart \\
\hline 1 & & + & 0 \\
2 & 'Protracted' acute hepatitis & + & 0 \\
3 & 'Protracted' acute hepatitis & 0 & 0 \\
4 & 'Protracted' acute hepatitis & + & 0 \\
5 & & + & 0 \\
6 & 'Non-protracted' acute hepatitis & 0 & 0 \\
7 & 'Non-protracted' acute hepatitis & 0 & \\
8 & Obstructive jaundice & 0 & 0 \\
9 & Obstructive jaundice & 0 & 0 \\
10 & Cholecystitis & 0 & 0 \\
11 & Carditis & 0 & \\
12 & Carditis & 0 & + \\
13 & Carditis & + & + \\
14 & Carditis & 0 & 0 \\
15 & Carditis & 0 & + \\
16 & Carditis & 0 & 0 \\
17 & Carditis & 0 & 0 \\
& & 0 & + \\
& & 0 & +
\end{tabular}


frequently appear as tiny particles under the microscope, the presence of dust or other granules in the preparation may easily give rise to errors; excessively turbid sera should not be used. Parallel analysis was carried out on the sera of adults suffering from various hepatic diseases and those of children suffering from carditis. Homogenized human liver and heart served as antigens. Results are summarized in Table IV.

The serum of one of the eight cardiac children reacted positively both with the heart and the liver antigen: the antihuman globulin consumption test was likewise positive in this case with both antigens.

\section{DISCUSSION}

These results justify the conclusion that the thrombocyte consumption test can be used to demonstrate autoantibody-like serum factors which react with homologous tissues. The reaction is based on the phenomenon of 'serological adhesion' (Lamanna, 1957; Nelson and Nelson, 1959) which is a twophased process. First, the antigen-antibody-complement complex is formed, and to this, as a second step, the receptor substance covering the thrombocyte surface is linked. The hypothetical compound in the blood serum promoting the linking was named 'thrombocytobarin' by Kritschewsky and Tscherikower (1925). The precise mechanism of linking is not yet known. According to our observations, if we first added the serum containing the antibodies to the antigen, and only afterwards the complement and plasma containing thrombocytes were added to the system we obtained less satisfactory results.

The method under investigation has the advantage of simplicity. It does not require a serial cold washing of the mixture antigen-test serum, nor does it require an indicator system. This may be why no positive reaction occurred either in the sera of patients suffering from 'other' internal diseases or in those of the healthy individuals. On the other hand, $40 \%$ of the patients with infections did give positive reactions which can be explained in two ways. First, in the various infections with a positive thrombocyte con- $\vec{F}$ sumption test (Table II) the bacterial or virus infec- $\stackrel{\text { ? }}{+}$ tion or toxic impact may have injured the liver parenchyma sufficiently to promote the formation of $\frac{\overline{\bar{O}}}{\overline{\mathrm{n}}}$ autoantibodies against the hepatic tissue. Secondly, $\vec{\sigma}$ the high positivity might be attributable to the hetero- $\varrho$ genous character of the antigen: liver homogenate $\&$ contains not only hepatic cells but connective-tissue $\vec{\circ}$ elements as well. Possibly the antibodies demonstrated are not liver but connective tissue specific. $\vec{\omega}$ Further investigations of this hypothesis are in $\frac{2}{8}$ progress. ce ar the Heim Pál Has chice Hospital, and to Dr. Éva Kálmán for the blood serum of children with $\rightarrow$ carditis and for the heart antigen.

\section{REFERENCES}

Bier, O. G., ana Siqueira, M. (1959). Proc. Soc. exp. Biol. (N. Y.), 101, 502.

Bálint, P., and Hegedüs, A. (1959). Klin. lab. diagn. 159.

Hoigné, R., and Storck, H. (1953). Schweiz. med. Wschr., 83, 718.

Korossy, S., and Gózony, M. (1959). Acta allerg. (Kbh.), 13, 286.

Lamanna, C. (1957). Bact. Rev., 21, 30.

Kritschewsky, I. L., and Tscherikower R. S. (1925). Z. Immun-Forsch., 42, 131.

Miescher, P., and Cooper, N. (1960). Vox Sang. (Basel), 5, 138.

Nelson, R. A. Jr., and Nelson, D. S. (1959). Yale J. Biol. Med., 31, 201.

Nilzén, A. (1953). Acta derm.-venerol. (Stockh.), 33, 456.

Osler, A. G., Hawrisiak, M. M., Ovary, Z., Siqueira, M., and Bier, O. G. (1957). J. exp. Med., 106, 811

Osztovics, M., Marcsek, Z., and Szász, G. (1962). Gyermekgyógyászat, $13,97$.

Rice, C. E. (1955). J. Immunol., 75, 85.

Rieckenberg, H. (1917). Z. Immun-Forsch., 26, 53.

Rissel, E., Steffen, C., and Wewalka, F. (1957). Wien. klin. Wschr., 69, 885.

Rocha e Silva, M. (1950). Ann. N.Y. Acad. Sci., 50, 1045.

Siqueira, M., and Nelson, R. A. Jr. (1961). J. Immunol., 86, 516.

Stavitsky, A. B., Stavitsky, R., and Ecker, E. E. (1949). Ibid., 63, 389.

Steffen, C. (1954). Wien. Z. inn. Med., 35, 422.

(1955). Klin. Wschr., 33, 134.

—, and Schindler, H. (1955). Schweiz. Z. Path., 18, 287.

Storck, H., and Hoigné, R., (1956). Dermatologica, (Basel), 112, 405. Koller, F. (1951) Schweiz. med. Wschr., 81, 195.

- (1951). In C.r.I. Congr. internat. Allerg. Zürich, Karger, Basel, 1952.

Vorländer, K. O., (1954). Verh. dtsch. Ges. inn. Med., 60, 242. 